Research Article

\title{
Increasing the Hydraulic Conductivity of Solidified Sewage Sludge for Use as Temporary Landfill Cover
}

\author{
Xihui Fan, ${ }^{1}$ Wei Zhu $\mathbb{D},{ }^{2}$ Yongjin Qian, ${ }^{1}$ Siling Wu, ${ }^{1}$ Shi Shu, ${ }^{1}$ and Naixi Lin $^{2}$ \\ ${ }^{1}$ Geotechnical Research Institute, Hohai University, Nanjing 210098, China \\ ${ }^{2}$ College of Environment, Hohai University, Nanjing 210098, China \\ Correspondence should be addressed to Wei Zhu; zhuweiteam.hhu@gmail.com
}

Received 15 March 2019; Revised 21 May 2019; Accepted 23 May 2019; Published 12 June 2019

Academic Editor: Flavio Stochino

Copyright (c) 2019 Xihui Fan et al. This is an open access article distributed under the Creative Commons Attribution License, which permits unrestricted use, distribution, and reproduction in any medium, provided the original work is properly cited.

Using sewage sludge as temporary cover for landfills is one of the most effective methods to dispose sludge. The mechanical properties of solidified sludge usually meet the requirements for temporary landfill cover, but its low permeability can cause problems due to formation of perched leachate. This study focused on the effect of solidification and remolding on hydraulic conductivity of sludge and conducted permeability tests on sludge solidified by using either ordinary Portland cement (OPC) or sulphoaluminate cement (SAC). The related pore structure and aggregate size distribution were analyzed later by the mercury intrusion pressure (MIP) method and soil water characteristic cure (SWCC) method. The experiment results show that the hydraulic conductivity of solidified sludge was in the range of $10^{-7} \sim 10^{-6} \mathrm{~cm} / \mathrm{s}$. When sludge is solidified with an SAC dosage $>40 \%$ and remolded after curing for 7 days, its hydraulic conductivity increases sufficiently to the order of $10^{-4} \mathrm{~cm} / \mathrm{s}$. The trend for solidified sludge exhibited a power function relation between the logarithmic hydraulic conductivity and the proportion of macropores. Overall, it can be concluded that the increase of hydraulic conductivity is attributed to the development of an aggregate structure, with water being transmitted mainly through the interaggregate pores; therefore, the sludge could be used as temporary landfill cover.

\section{Introduction}

Sewage sludge is a by-product of wastewater treatment. With the construction of new sewage treatment plants and the increase of sewage treatment ratio, sewage sludge production in China has risen significantly, with an average annual growth of $13 \%$ [1]. In 2017, China's total sewage wastewater output was about 70 billion tons [2]. Based on the assumption of 0.8 ton sludge ( $80 \%$ water content) per kiloton of wastewater, 56 million tons of sewage sludge were produced in 2017 in China. Definitely, this figure is expected to grow. Although incineration, land application, and other reuse of sludge are encouraged in China, more than $60 \%$ of the sludge is deposited in landfills [1]. The undrained shear strength of sludge can be as low as $0.5 \sim 7 \mathrm{kPa}$ [3], so dumping the sewage sludge into landfills without any treatment will not only reduce the limited storage capacity of the landfills but also result in landfill instability and difficulties in operation [4]. Some guidelines are recommended to use the sewage sludge as the alternative daily or intermediate covers in landfills, which employed soil as the traditional method $[5,6]$. Modifying the sludge to be a soil-like material and to serve as a suitable temporary cover can alleviate the problem of landfill storage capacity and disposal of sludge.

The solidified sludge becomes strong enough to maintain landfill stability and can withstand rolling compaction [7]. However, the hydraulic conductivity $(k)$ after solidification is generally below $10^{-6} \mathrm{~cm} / \mathrm{s}$ and can be as low as $10^{-9} \mathrm{~cm} / \mathrm{s}$ $[8,9]$, while $k$ of municipal soil waste (MSW) is about $10^{-2} \sim 10^{-3} \mathrm{~cm} / \mathrm{s}$ [10]. Percolation of rainwater through the surface of landfill generates much leachate, which needs to be disposed by different methods [11]. The difference in permeability between MSW and temporary cover is one of the main reasons for the presence of perched leachate $[12,13]$. The formation of multilayered perched leachate in the Jiangcungou landfill in Xi'an, China, was caused by the 
low hydraulic conductivity of the loess used as temporary cover material [14]. In Qizishan landfill in Suzhou, China, a layer of perched leachate several meters thick was formed above the intermediate cover, which had a $k$ value around $4 \times 10^{-7} \mathrm{~cm} / \mathrm{s}$ [12]. The ideal hydraulic conductivity of temporary cover shall be neither too high nor too low [15]. If its hydraulic conductivity is too high, the temporary cover layer will not prevent the infiltration of precipitation into the landfill; if the hydraulic conductivity is too low, it may block leachate migration and cause the formation of perched leachate. In both cases, the stability of the landfill may be compromised $[5,16]$. Although precipitation intensity varies in different parts of China, temporary cover layers with $k$ values of $10^{-4}$ to $10^{-5} \mathrm{~cm} / \mathrm{s}$ are recommended in most regions [7]. The hydraulic conductivity of solidified sludge should be increased for the suitable temporary cover material.

The macroscopic parameter (e.g., hydraulic conductivity) of porous material is a reflection of its microstructure [17]. Hydraulic conductivity, $k$, is a function of the void ratio and pore structure and can be predicted by statistical analysis of the pore size distribution $[18,19]$. In HagenPoiseuille flow, hydraulic conductivity is proportional to the square of the pore radius $(r)$. Macropores have more influence on the hydraulic conductivity than micropores. Organic soils or clayey soils generally have aggregate structure, and their pores can be divided into matric pores (intra-aggregate pores), structure pores (interaggregate pores, macropores), and fissures (or cracks, not considered in this paper) [20]. But the microstructure of sludge or solidified sludge is much more complicated. The organic content of dry sludge is about $50 \%$ by mass, which consists mainly of microorganisms, i.e., lipids, proteins, and polysaccharides, along with humus and other decomposing organic matter [21]. The bound water (osmotic, surface, and intracellular water) of the bioflocculate can impede water convection, and only free water (bulk water and some portion of interstitial water) can transmit [22]. Some clayey soils with similar microstructures have high hydraulic conductivity because of their aggregate structure, with relatively large interaggregate channels playing a major role in water transmission [23]. The hydraulic conductivity of the solidified sludge can be manipulated by controlling the processes of rolling and compaction after sludge solidification, which is usually done in engineering application. If the microstructure of the sludge can be modified to form a similar structure, large numbers of interaggregate pores would be formed, which can be served as channels for water transmission. Thus, the hydraulic conductivity of the sludge may become high enough for it to be used as an effective temporary landfill cover. It is necessary to study the hydraulic conductivity of solidified sludge and analyze the remolding influence on a macroscopic property (hydraulic conductivity) and microstructure properties, i.e., aggregate and pore size distribution.

This study firstly employed hydraulic conductivity tests and microstructure analysis for the purpose of systematically studying the influence of solidification and remolding on hydraulic conductivity of sewage sludge and to see whether the hydraulic conductivity could be increased to become suitable for temporary landfill cover materials. In the end, sludge solidification method for landfill temporary cover was discussed.

\section{Materials and Methods}

2.1. Materials and Sample Preparation. The sludge for this study was obtained from a wastewater treatment plant in Nanjing, China. The physical properties of the sludge were determined using the analytical methods specified by the Ministry of Construction of the People's Republic of China [24] and are provided in Table 1. One of the solidifying agents is Portland cement (OPC), commonly used in engineering applications, and the other is sulfoaluminate cement (SAC), recommended by Sun [25], thanks to its high early strength. Both of them have a cement grade of 42.5 , and their mineral composition can be found in [25].

To prepare the solidified sludge, OPC or SAC (mass ratio content of cement to wet sludge at $10 \%, 20 \%, 30 \%, 40 \%$, and $50 \%)$ was mixed with sewage sludge. Solidified samples were then prepared by injecting the mixture into plastic molds and leaving them there until the samples had been cured. The molds were vibrated to prevent bubble formation in solidifying sludge, which has a water content close to the liquid limit.

Remolded solidified samples were produced by curing the mixture in plastic bags and then remolding them. In the remolding process, the solidified sludge was pulverized with a rubber hammer, passed through a $2 \mathrm{~mm}$ sieve, and then compacted according to Chinese Standard GB/T 50123-1999 [24] in three layers of equal thickness. The surface of each layer was scarified for uniformity before the next layer was added.

All the samples were cured in a curing box with a relative humidity of $95 \%$ and a temperature of $20^{\circ} \mathrm{C} \pm 2^{\circ} \mathrm{C}$. Solidified sludge samples were cured for $7,14,28$, and 56 days, respectively. Remolded samples were cured for 7 days before remolding. After remolding, they were either not cured or cured for another 21 days. The microstructure, hydraulic conductivity, and geotechnical properties of the remolded samples were compared with those of the solidified sludge with identical total curing time of 7 or 28 days.

2.2. Hydraulic Conductivity Test. Hydraulic conductivity was determined using a flexible-wall permeameter designed by Nanjing Soil Instruments. The solidified or remolded samples were trimmed to a diameter of $70 \mathrm{~mm}$ and a height of $40 \mathrm{~mm}$ using a cutting ring. Samples were tested under a confining pressure of $50 \mathrm{kPa}$ to simulate typical overburden pressures, and the seepage pressure was set at $30 \mathrm{kPa}$ with deionized water. The tests were conducted in accordance with ASTM D5084 [26]. The tests were run until the standard termination criteria were met: (1) the ratio of outflow rate to inflow rate was between 0.75 and 1.25; and (2) at least two consecutive measurements of hydraulic conductivity $(k)$ were within $\pm 15 \%$ of each other. 
TABLE 1: Basic properties of sewage sludge.

\begin{tabular}{lcccc}
\hline $\begin{array}{l}\text { Specific gravity } \\
G_{\mathrm{s}}\end{array}$ & $\begin{array}{c}\text { Plastic } \\
\text { index (\%) }\end{array}$ & $\begin{array}{c}\text { Liquid } \\
\text { index (\%) }\end{array}$ & $\begin{array}{c}\text { Water } \\
\text { content (\%) }\end{array}$ & $\begin{array}{c}\text { Organic } \\
\text { content (\%) }\end{array}$ \\
\hline 2.2 & 53 & 130 & 426 & 54 \\
\hline
\end{tabular}

2.3. Aggregate and Pore Size Distribution Analysis. The aggregate size distribution after remolding was determined by the laser diffraction method. The pretreatment process was followed the method of Elliott [27], in which the remolded solidified sludge was submerged in water for 5 minutes before being continuously shaken for 2 minutes.

The pore size distribution was obtained from two different methods, viz, mercury intrusion pressure (MIP) method [28] and soil-water characteristic curve (SWCC) method [29], using a PoreMaster-60 porosimeter (Quantachrome Inc., USA) and a Himac CR21GIII centrifuge (Hitachi lnc., Japan), respectively. The calculation of pore radius is based on the theory that fluid will intrude the voids under pressure. The general form of pore size-capillary pressure relationship can be written in terms of applied intrusion pressure, $u$, as

$$
r=-\frac{2 T_{\mathrm{s}} \cos \alpha}{u}
$$

where $r$ is pore radius, $T_{\mathrm{s}}$ is surface tension, $\alpha$ is contact angle. In mercury test, $T_{\mathrm{s}}=485.5 \mathrm{mN} / \mathrm{m}\left(25^{\circ} \mathrm{C}\right)$ and $\alpha$ is about $140^{\circ}$ for mercury, and in centrifuge test, $T_{\mathrm{s}}=72 \mathrm{mN} / \mathrm{m}$ $\left(25^{\circ} \mathrm{C}\right)$ and $\alpha=0^{\circ}$ for water. The maximum mercury intrusion pressure was $138 \mathrm{MPa}$, which corresponds to a pore radius of about $0.005 \mu \mathrm{m}$. And the maximum centrifugal force was $\mathrm{pF}=4.2(1.58 \mathrm{MPa})$, with the corresponding minimum capillary pore radius $\approx 0.32 \mu \mathrm{m}$.

Although the MIP method and centrifuge method are both effective in determining the pore structure, they have different meanings. In MIP tests, the freeze-drying method is employed in preparing the samples, and all the water, including cell water and bound water, is sublimated. The volume of removed water corresponds to the total pore volume of the solidified sludge. In centrifuge tests, the relationship between matric suction and pore size is typically considered along the drying or drainage path. The capillary pore size distribution is obtained by subtracting the immobile water volume from the void volume of the solid phase. In the seepage process, the immobile water behaves like a solid phase that obstructs the transmission of water [30]. The MIP results are therefore a measure of the total pore size distribution, while the centrifuge tests measure the effective or capillary pore size distribution.

Soil water characteristic curve (SWCC) for use with equation (1), whereby the relationship between pore size distribution and matric suction can be established [31]. If dual-porosity structure exists, the following equation [32], which takes account of the matric and structural pore space, can be used to describe the water retention curve:

$$
\theta=C+A_{1} e^{\left(-h / h_{1}\right)}+A_{2} e^{\left(-h / h_{2}\right)},
$$

where $C$ is the residual water content and $A_{1}$ and $A_{2}$ are constants proportional to the amounts of intra-aggregate and interaggregate pore space, respectively. The values of $h_{1}$ and $h_{2}$ are the characteristic pore water-suction pressures at which the matric and structure pores empty, respectively.

2.4. Hydration Product Analysis. Thermogravimetric analysis (TGA) and X-ray diffraction (XRD) were used to identify the different hydration products resulting from solidification by OPC and SAC. Sludge, OPC40, SAC20, and SAC40 were analyzed in detail, all of which had been cured for 7 days.

$\mathrm{XRD}$ and TGA tests were carried out using a D8Advance X-ray diffractometer (Bruker. Inc., Germany) and an SDT-Q600 synchronous thermal analyzer (TA Instruments, USA), respectively. Before conducting the tests, the dried samples were milled into fine particles. The XRD patterns of the samples were obtained with a scanning rate of $5^{\circ} / \mathrm{min}$ from $5^{\circ}$ to $45^{\circ}$. In the TGA tests, $5-10 \mathrm{mg}$ of the dried sample was heated in a ceramic crucible from room temperature to $1,044^{\circ} \mathrm{C}$ at a heating rate of $10^{\circ} \mathrm{C} / \mathrm{min}$. The first derivative (DTG $(\% / \mathrm{min}))$ of the thermogravimetric curve (TG (\%)) was obtained to identify the amorphous and crystallized hydrates produced by hydration.

\section{Results and Discussion}

3.1. Influence of Cement Dosage and Curing Time on $k$. Figure 1 shows the hydraulic conductivity $(k)$ of sludge solidified with OPC and SAC after curing for 7 days. The cement dosage has little effect on the hydraulic conductivity of the solidified sludge. The $k$ value of the solidified sludge was in the order of $10^{-6}-10^{-7} \mathrm{~cm} / \mathrm{s}$. These $k$ values were close to those of sludge solidified by cement and bentonite [33] as well as raw sewage sludge [34]. In this sense, solidified sludge with this hydraulic conductivity is not suitable for use as landfill temporary cover material.

Figure 2 displays the hydraulic conductivity of samples OPC30, OPC40, SAC30, and SAC40; each had been cured for $7,14,28$, and 56 days. The longer curing time for solidified sludge did not change its hydraulic conductivity significantly, and the data still remained in the range of $10^{-6}-10^{-7} \mathrm{~cm} / \mathrm{s}$.

3.2. Influence of Remolding Process on $k$. Figures 3(a) and 3(b) exhibit the change of hydraulic conductivity immediately after remolding. This sample had been cured for 7 days. Figures 3(c) and 3(d) show the effects of remolding on the hydraulic conductivity of samples that had been cured for a total of 28 days. The left $Y$ axis represents the hydraulic conductivity of the remolded solidified sludge, and the right $Y$ axis represents the ratio of hydraulic conductivity after and before remolding, $k_{\text {remolded }} / k_{\text {intact }}$.

As can be seen in Figure 3(a), the OPC solidified sludge hydraulic conductivity is of the same order of magnitude for all the cement dosages tested, and $k_{\text {remolded }} / k_{\text {intact }}$ is slightly less than 1 , meaning that remolding caused a slight decrease in hydraulic conductivity. The decreased permeability might be caused by the dispersed and oriented structure induced by remolding [35]. Figure 3(b) shows the hydraulic 


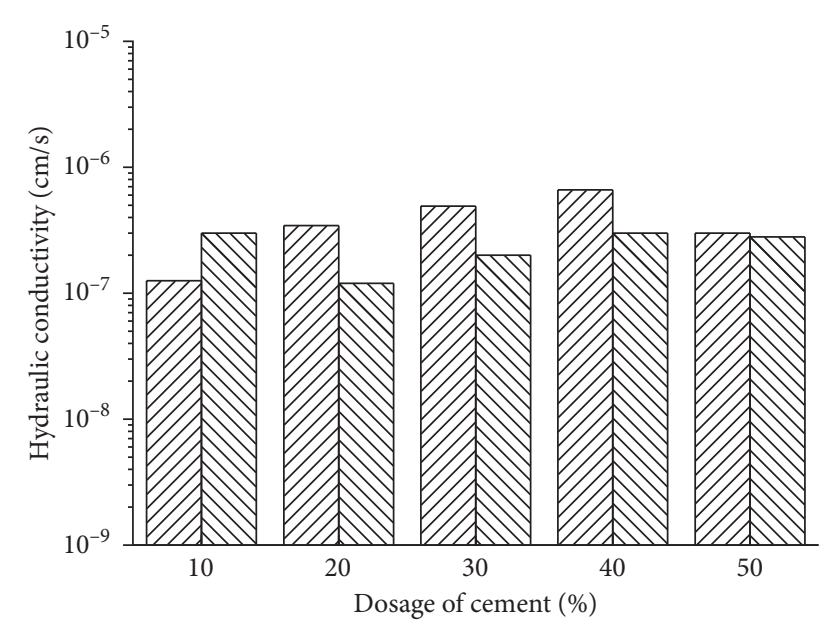

VIIA OPC MIV SAC

FIGURE 1: Hydraulic conductivity of solidified sludge with different cement dosages.

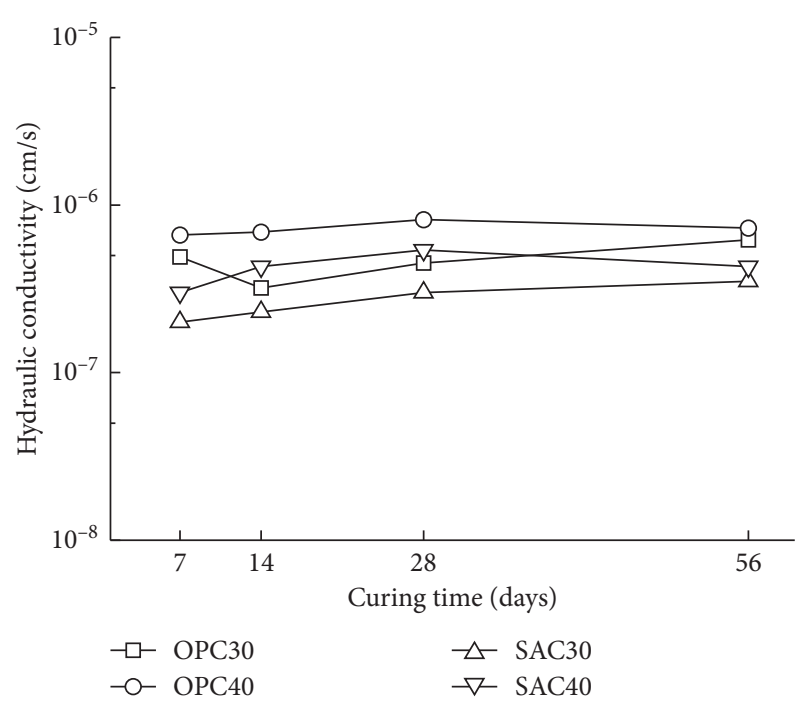

Figure 2: Effect of curing time on hydraulic conductivity of solidified sludge.

conductivity of SAC-cured sludge after remolding. The hydraulic conductivity did not change much with the addition of less than $30 \%$, but it increased dramatically when the SAC dosage was greater than $40 \%$. It seems that the microstructure has changed. At this dosage, the hydraulic conductivity can approach $10^{-4} \mathrm{~cm} / \mathrm{s}$, the nature of which is close to a suitable temporary cover material with hydraulic conductivity of $10^{-4}-10^{-5} \mathrm{~cm} / \mathrm{s}$. Figures $3(\mathrm{c})$ and $3(\mathrm{~d})$ illustrate that the hydraulic conductivity of solidified sludge with an additional 21 days of curing after remolding was not markedly different from that of the specimens in Figures 3(a) and 3(b).

3.3. Variation of Aggregate and Pore Size Distribution. Remolding is the process of reformation of the aggregate structure and pore size distribution of the solidified sludge.
Solidification process increases the strength and cohesiveness of the material, which has an effect on the aggregate structure and pore structure. Figure 4 reveals the aggregate size distribution of OPC- and SAC-solidified sludge after remolding. With the addition of cement, the size of the aggregate particles increased after remolding. However, the OPC-solidified sludge still had a unimodal particle or aggregate size distribution, with the peak occurring at $20-30 \mu \mathrm{m}$. By contrast, when the SAC content was greater than $40 \%$, the particle size distribution of the remolded specimens became bimodal, with one peak occurring at a particle size of $60 \mu \mathrm{m}$ and the other peak occurring at around $400 \mu \mathrm{m}$. SAC40 and SAC50 even developed large particles with radii above $1 \mathrm{~mm}$.

Figure 5 shows the pore size distribution of OPCsolidified sludge determined from MIP tests. The vertical axis in the figure is $d V / d \log (r)$, where $r$ is the entrance pore size radius and $d V$ is the volume of the pores whose radius is $r$. The solidified sludge has a bimodal distribution with one peak at around $8 \mu \mathrm{m}$ and the other at around $0.6 \mu \mathrm{m}$. With the increase of cement dosage, the volume of pores with $r \approx 8 \mu \mathrm{m}$ decreased and the smaller pores increased. However, it can be found in Figure 1 that there exists no evident difference in terms of hydraulic conductivity of the four kinds of solidified sludge. It can be concluded that the decreased $8 \mu \mathrm{m}$ pores are "inactive" pores, which cannot change the permeability. In order to verify this, capillary pore size distribution was conducted.

Figure 6 illustrates the capillary pore size distribution of OPC-solidified sludge determined from centrifuge tests. The effective pores of the solidified sludge have a unimodal distribution, and the peak value ranges from 0.5 to $1.0 \mu \mathrm{m}$, which corresponds to the main peak measured by MIP tests in Figure 5. However, the macropores with radii of around $8 \mu \mathrm{m}$ found in the MIP tests are not reflected in this effective pore size distribution (Figure 6).

Figure 7 shows the capillary pore size distribution of the samples that were remolded after curing time of 7 days. Figure 7(a) displays the pore size distribution of samples immediately after remolding. The same data for samples cured for a further 21 days are shown in Figure 7(b). The effective pores of remolded OPC-solidified sludge have a unimodal distribution similar to that before remolding, with the peak of the distribution occurring in the pore radius range of $0.5-1.0 \mu \mathrm{m}$. The effective pore-size distribution of SAC-solidified sludge differed when the amount of SAC added exceeded $40 \%$. In this case, the effective pore-size distribution was bimodal, with an extra peak at around $10 \mu \mathrm{m}$. Similar results have been reported in the literatures, and they attributed the reason to the formation of an aggregate structure, as opposed to oriented $[35,36]$. Only a small fraction of the unclogged macroporosity volume contributes to the most fluid flow through the soil structure [37].

3.4. Hydration Products. The difference in the formation of the aggregate structure and dual pore structure after remolding was caused by the hydration reactions of OPC and SAC. The identities and yields of the hydration products 


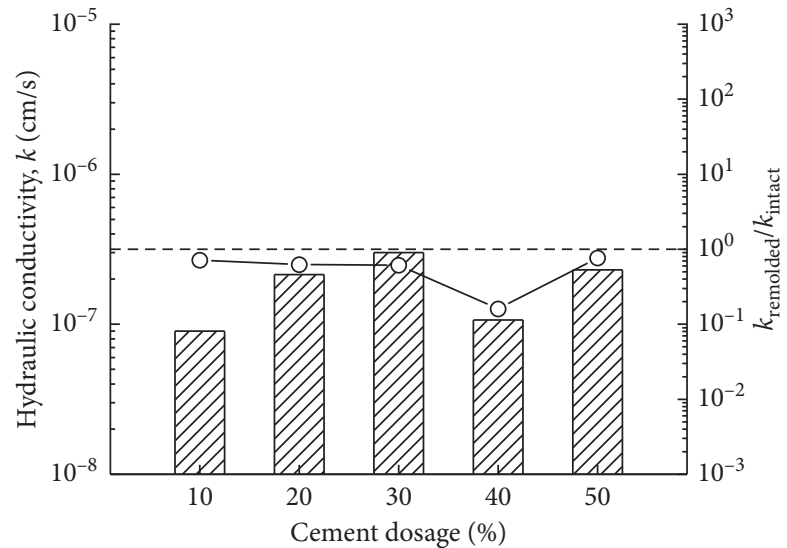

UIIA $k$-Re-OPC-7/0 -O- $k_{\text {remolded }} / k_{\text {intact }}$

(a)

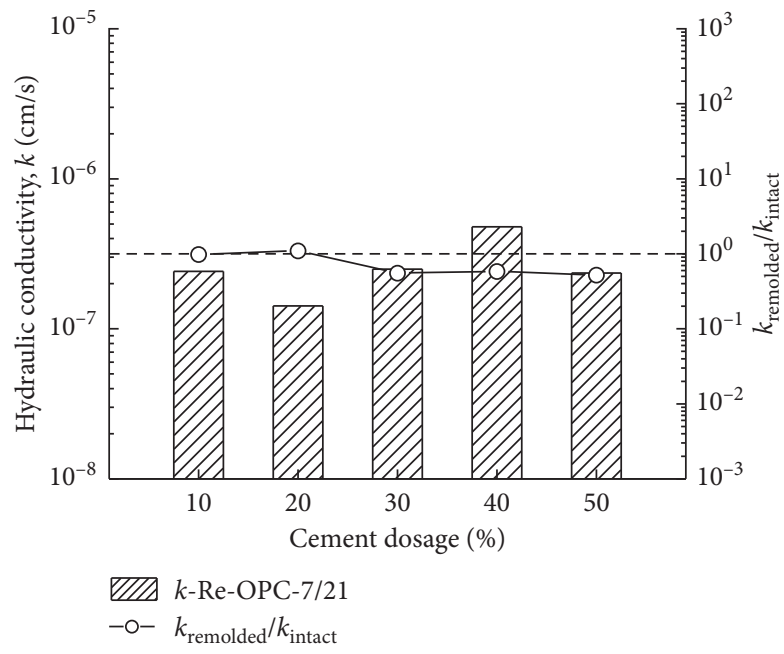

(c)

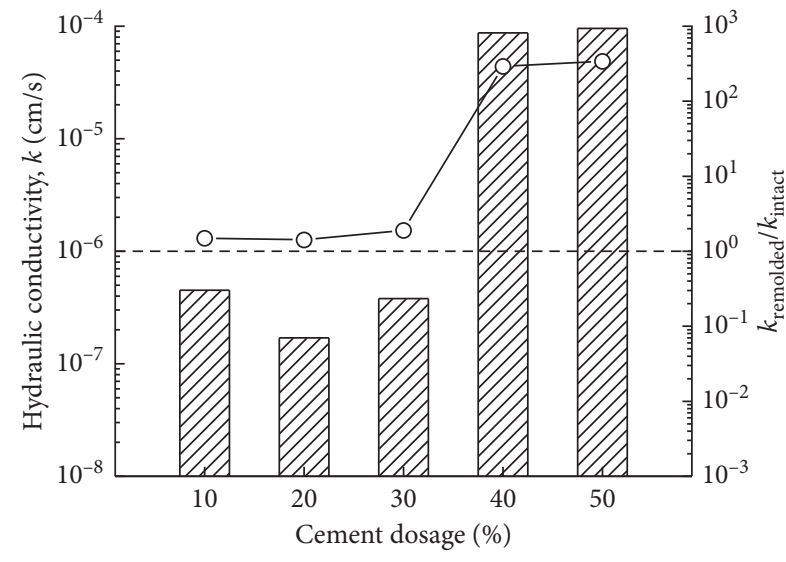

VIIA $k$-Re-SAC-7/0

$-\mathrm{O}-k_{\text {remolded }} / k_{\text {intact }}$

(b)

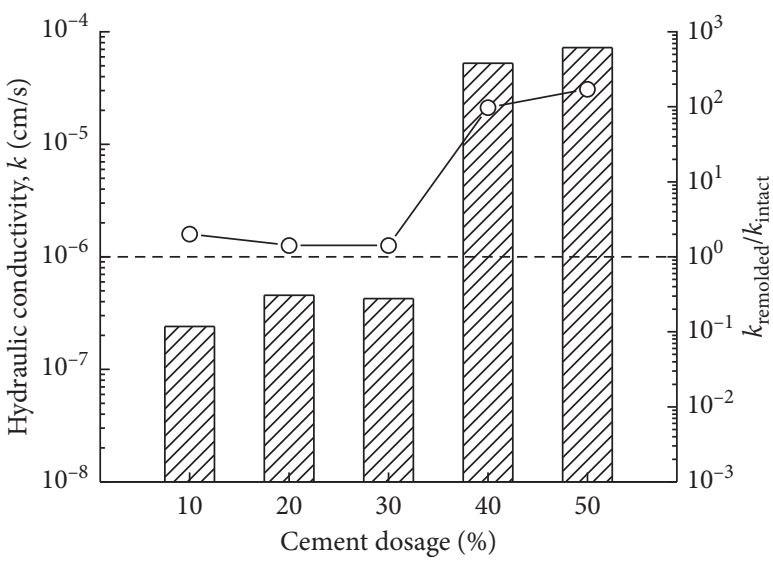

WIIA $k$-Re-SAC-7/21

-O- $k_{\text {remolded }} / k_{\text {intact }}$

(d)

FIGURE 3: Effect of remolding on $k$ of solidified sludge: (a) OPC-7/0; (b) SAC-7/0; (c) OPC-7/21; (d) SAC-7/21. Note: XXX-(i)/(j) indicates that the curing time of XXX-solidified sludge before and after remolding is $(i)$ days and $(j)$ days, respectively.

resulting from the use of the two different solidifying agents on sewage sludge were investigated by TGA and XRD.

Figure 8 shows the XRD patterns of four materials: sludge, OPC40, SAC20, and SAC40. The main inorganic component of the sludge is quartz (silica, $\mathrm{SiO}_{2}$ ). This result is consistent with the study by Chin [38]. The hydration products of OPC solidification were calcium silicate hydrates (CSH), calcium silicate aluminate hydrates (CASH), and a small amount of ettringite. When SAC was used for solidification, the main hydration product was ettringite, the quantity of which increased in proportion to the amount of SAC added.

Figure 9 shows the characteristic shapes of the TGA/ DTG curves of the sludge, SAC20, SAC40, and OPC40. The main decomposition of the sludge was in the range of $260-300^{\circ} \mathrm{C}$, which was mainly caused by the decomposition of carbohydrates and lipids [21]. The initial mass loss of the cemented sludge occurs at around $100^{\circ} \mathrm{C}$ and is largely owing to the dehydration of $\mathrm{CSH}, \mathrm{CASH}$, and ettringite [39]. DTG of the three hydration products was overlapped, making them difficult to distinguish. From TGA and XRD analysis, the SAC40 contained more hydration products than the other mixtures. Ettringite constituted the bulk of the hydration products present in SAC40. The presence of a high fraction of crystalline ettringite in SAC40 rather than the gelatinous $\mathrm{CSH}$ and $\mathrm{CASH}$ that were mostly presented in the other solidified sludges enhanced the mechanical strength of SAC40 and helped maintain its aggregate structure after remolding and compaction. The formation of the aggregate was caused not by compaction with a lower-than-optimal water content [40] but by the hydration products formed during the solidification process. The cemented sludge was broken into small aggregates (or particles) during the remolding process, which formed an aggregate structure that can withstand rolling compaction or other external forces.

3.5. Influence of Effective Macropores on $k$. The presence of macropores between the aggregate particles is the main reason for the increased hydraulic conductivity of the 


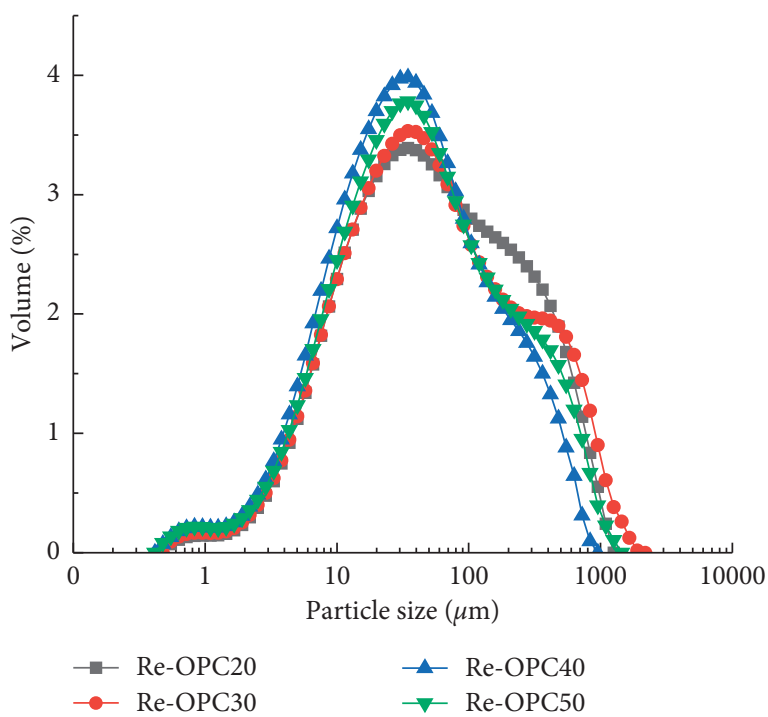

(a)

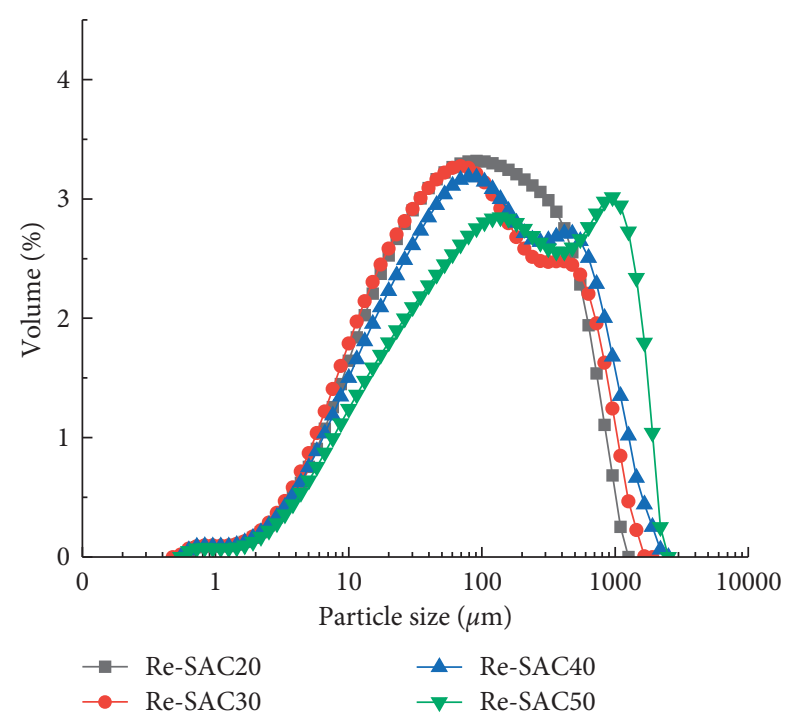

(b)

Figure 4: Particle size distribution of the solidified sewage sludge.

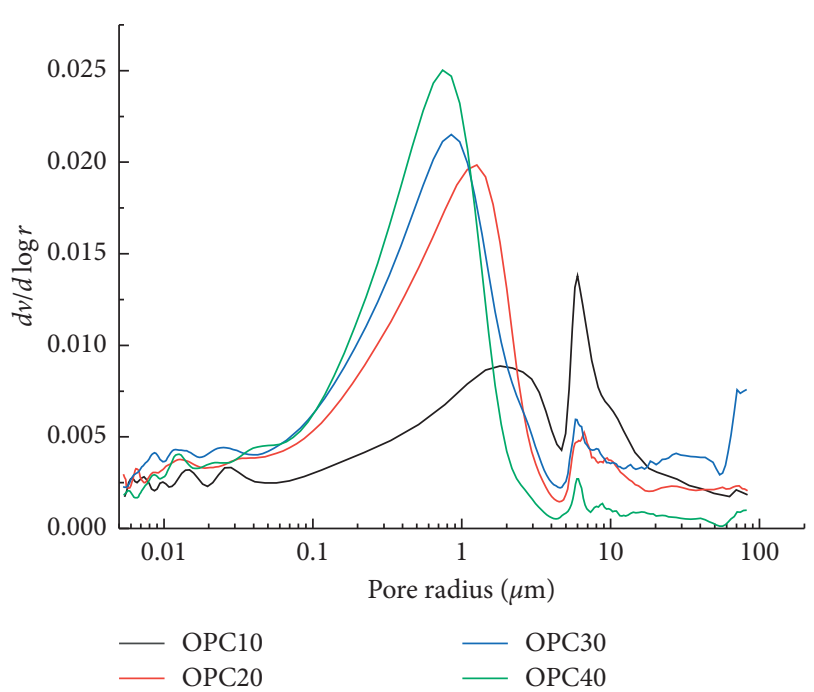

Figure 5: Pore size distribution of OPC-solidified sludge determined from MIP tests.

remolded solidified sludge. The experimentally determined hydraulic conductivity of solidified sludge is very low, namely, in the range of $10^{-6}-10^{-7} \mathrm{~cm} / \mathrm{s}$, making it unsuitable to be the temporary cover material. With SAC content of $40 \%$ or higher, the hydraulic conductivity increased after remolding to the order of $10^{-4} \mathrm{~cm} / \mathrm{s}$, which is close to the ideal range for temporary cover material. Solidified sludge generally has a large pore volume, with a void ratio of about 3-4. As shown in Figures 6 and 7, most of the pores were between $0.5 \mu \mathrm{m}$ and $1.0 \mu \mathrm{m}$, which is the main reason for the low hydraulic conductivity. The pore structure changed after remolding, but SAC-solidified sludge with low cement content and OPC-solidified sludge both have a unimodal pore size distribution. The SAC-solidified sludge with cement content greater than $40 \%$ remains in an aggregate

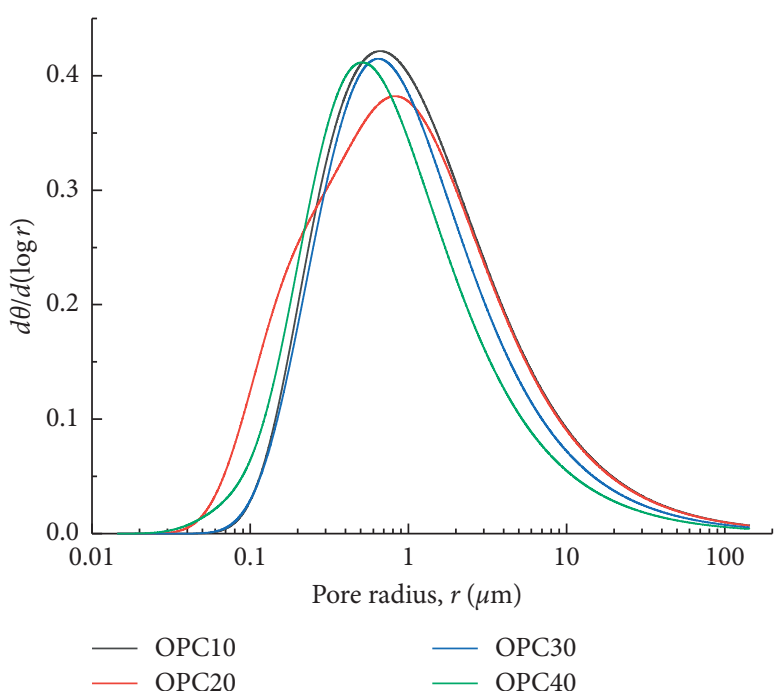

FIgURE 6: Effective pore size distribution of OPC-solidified sludge from centrifuge tests.

structure and can have greater strength, thanks to more hydration products. The strong skeleton formed by SAC resists compression forces and leads to the formation of a dual pore structure, with smaller intra-aggregate pores and larger interaggregate pores. The increase in the hydraulic conductivity after remolding occurs because the interaggregate pores transmit most of the water that percolates through the solidified sludge.

Pore radius of $10 \mu \mathrm{m}$ was assumed as the boundary between the interaggregate and intra-aggregate pores [41]. To further look into the effect of the proportion of macropores on permeability, the values of hydraulic conductivity reported in preview studies [35, 42-44] as well as those obtained from this study are plotted together on a semilogarithmic scale, as shown in Figure 10. It is clearly 


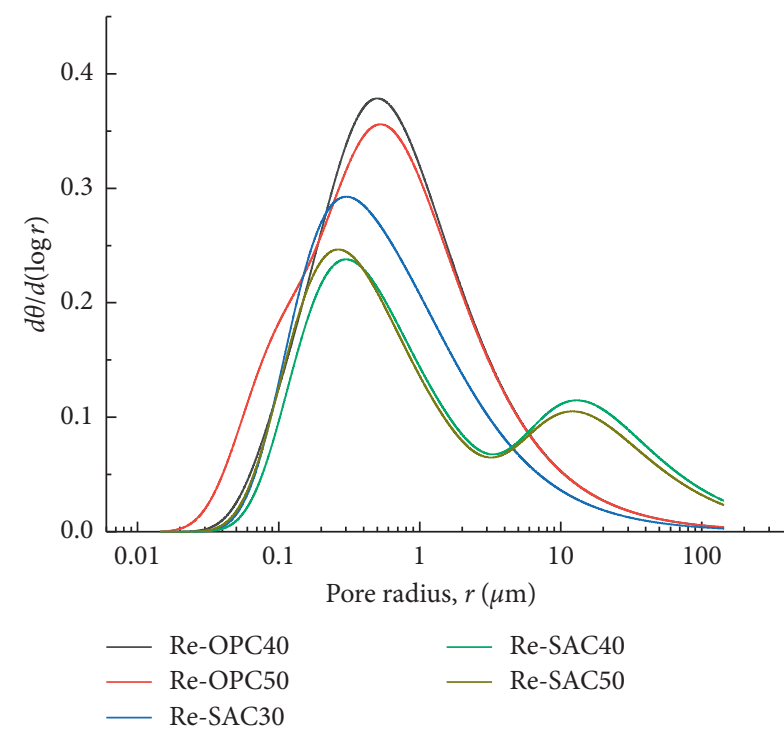

(a)

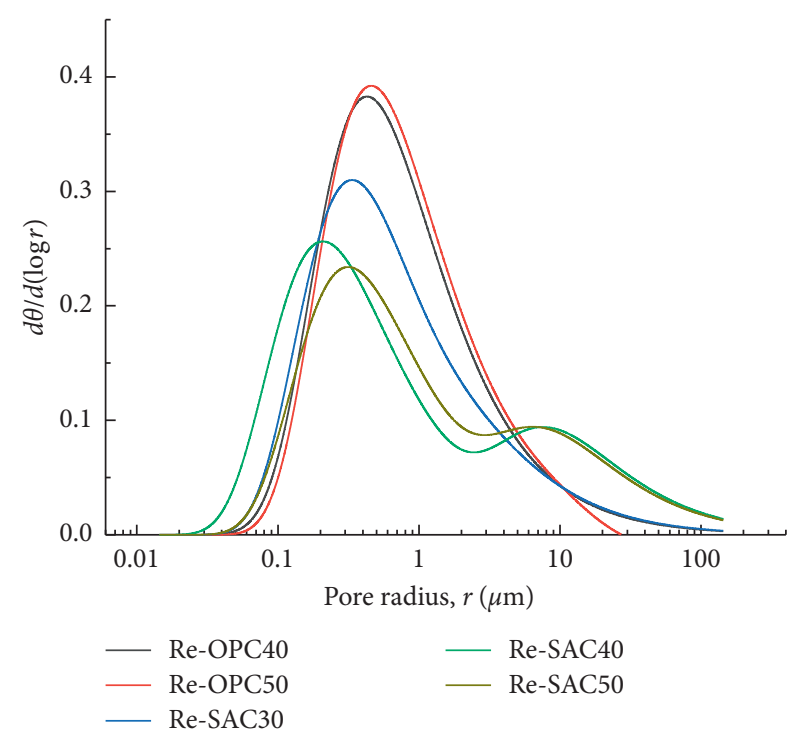

(b)

FIgURE 7: Effective pore-size distribution of remolded solidified sludge. (a) Time $=7 / 0$ days. (b) Time $=7 / 21$ days.

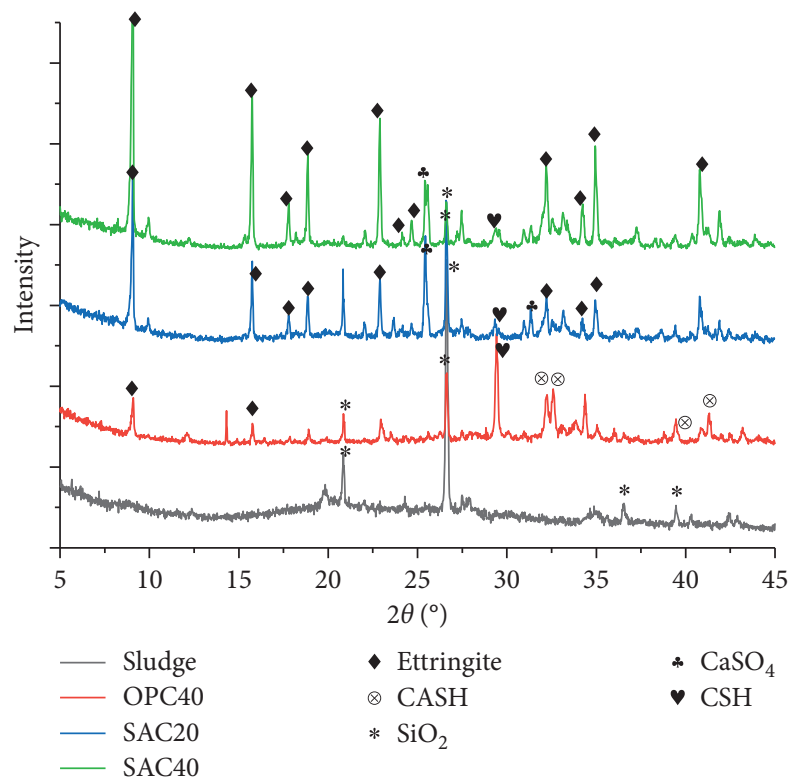

FIGURE 8: XRD patterns of the solidified samples and sludge.

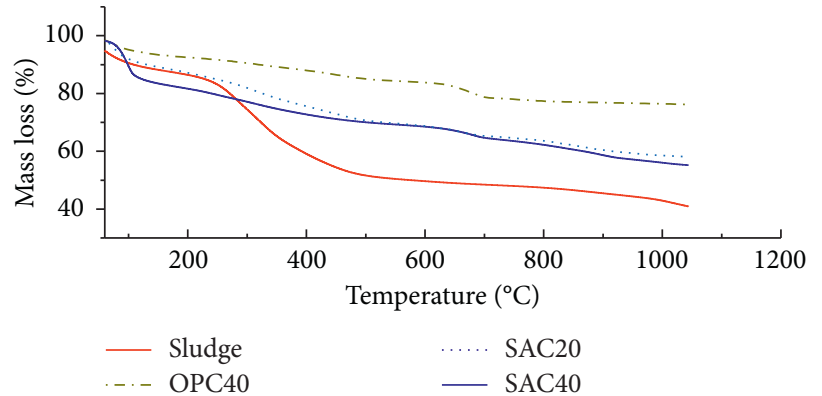

(a)

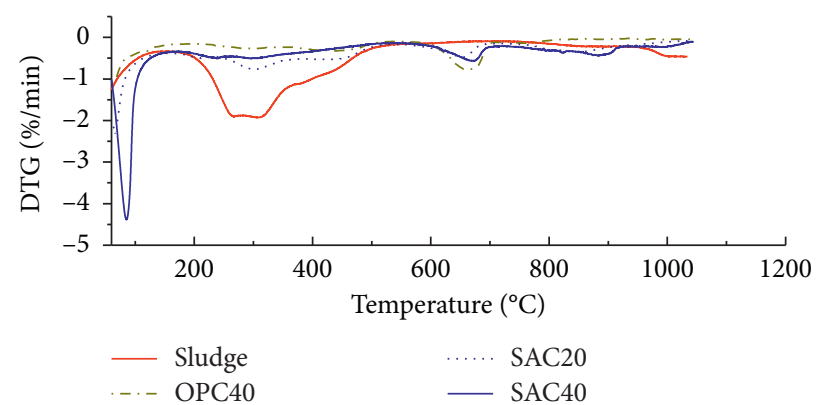

(b)

Figure 9: TGA curves after 7-day curing. 


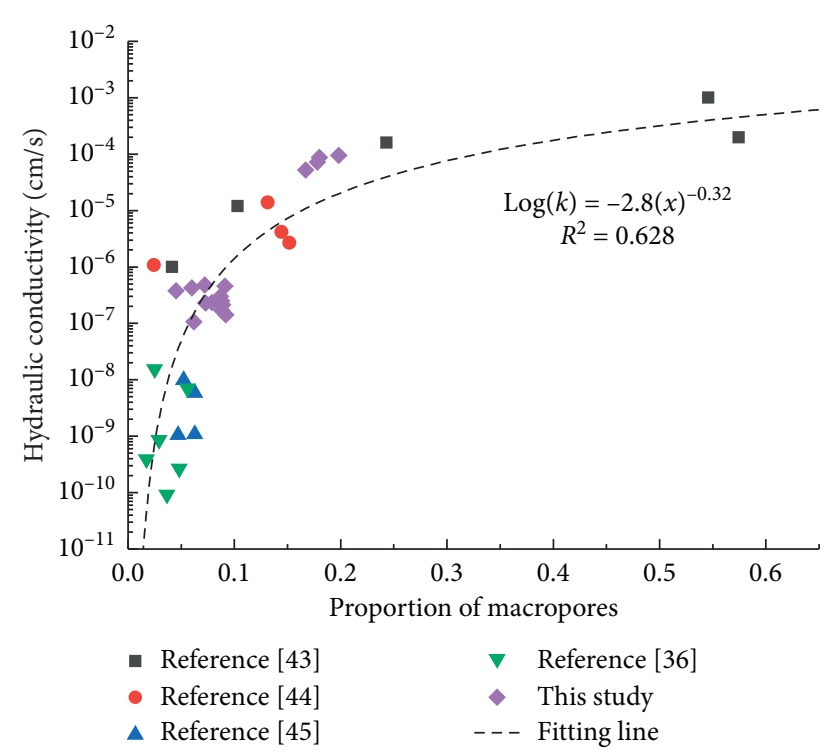

FIGURE 10: Variation of hydraulic conductivity with proportion of macropores.

indicated that the hydraulic conductivity tends to increase with the proportion of macropores. Note that the hydraulic conductivity changes significantly when the proportion of macropores is less than 0.2 , while it changes slightly when the proportion of macropores is more than 0.2. It is completely reasonable since the larger the pore size, the less resistance the water will experience when flowing through the solidified sludge [9]. The four points of remolded solidified sludge with SAC content greater than $40 \%$ in Figure 10 have a higher macropore proportion (about 20\%) and were likely to form an aggregate structure with large pore size, leading to higher hydraulic conductivity.

3.6. Sludge Solidification Method for Temporary Landfill Cover. It can be found that remolded solidified sludge with a SAC content greater than $40 \%$ and curing time of 7 days met the requirements for landfill temporary cover. The stiff aggregate in this solidified sludge formed a strong skeleton to bear the compaction load while maintaining the aggregate structure. The amount of additive required, $40 \%$, was relatively high. Common composite materials used as solidifying agents, such as bentonite, fly ash, and kaolinite, can potentially be used to reduce cement usage [8]. Provided that enough additive is used and that the curing time is enough, the solidified sludge can be strong enough for its aggregate structure to withstand rolling compaction. If treated in this way, the solidified sludge will be strong enough and can have sufficient hydraulic conductivity to serve as an effective temporary cover material in landfills.

\section{Conclusions}

(1) The hydraulic conductivity of solidified sludge (i.e., sludge with a water content of $80 \%$ and organic matter content of $50 \%$ of the solid mass) is on the order of $10^{-6}-10^{-7} \mathrm{~cm} / \mathrm{s}$, which is too low for temporary landfill cover. However, the hydraulic conductivity of remolded sludge with a SAC content greater than $40 \%$ increased to on the order of $10^{-4} \mathrm{~cm} /$ $\mathrm{s}$, making it an ideal temporary cover material.

(2) The OPC- and low-SAC-solidified sludge had a unimodal pore size distribution after remolding, while the solidified sludge with a SAC content greater than $40 \%$ formed an aggregate structure with a bimodal pore size distribution. The solidified sludge exhibits a power trend between the logarithmic hydraulic conductivity and proportion of macropores. The interaggregate pores in the highSAC solidified sludge have the capacity to transmit water and thus increase the hydraulic conductivity of the material.

(3) SAC in sufficient quantities undergoes rapid hydration reactions that generate a high fraction of crystalline ettringite rather than the gelatinous CSH and CASH that result from the hydration of OPC. The mechanical strength of the ettringite helps preserve a favorable aggregate structure and bimodal pore-size distribution with both intra- and interaggregate pores presented after remolding.

(4) Sewage sludge was thus successfully modified to form an aggregate structure with mechanical and hydraulic properties that make it an ideal alternative landfill temporary cover material.

\section{Data Availability}

The data used to support the findings of this study are available from the corresponding author upon request.

\section{Conflicts of Interest}

The authors declare that they have no conflicts of interest regarding the publication of this paper.

\section{Acknowledgments}

This study was financially supported by the Fundamental Research Funds for the Central Universities (2015B35614) and the National Program on Key Basic Research Project of China (973 Program) (2015CB057803).

\section{References}

[1] G. Yang, G. Zhang, and H. Wang, "Current state of sludge production, management, treatment and disposal in China," Water Research, vol. 78, pp. 60-73, 2015.

[2] China Statistic Press, China Statistical Yearbook 2018, China Statistic Press, Beijing, China, 2018.

[3] T. L. Zhan, X. Zhan, W. Lin, X. Luo, and Y. Chen, "Field and laboratory investigation on geotechnical properties of sewage sludge disposed in a pit at Changan landfill, Chengdu, China," Engineering Geology, vol. 170, pp. 24-32, 2014.

[4] L. Zhan, X. Luo, R. Guan et al., "Failure mechanism of sludge pit and downstream waste slope of a MSW landfill," Chinese Journal of Geotechnical Engineering, vol. 35, pp. 1189-1196, 2013. 
[5] F. G. Pohland and J. T. Graven, Use of Alternative Materials for Daily Cover at Municipal Solid Waste Landfills, EPA, Washington, DC, USA, 1993.

[6] V. Joosten, Alternate Daily Cover for Municipal Solid Waste Landfills, Waste and Materials Management Bureau, Madison, WI, USA, 2014.

[7] J. He, F. Li, Y. Li, and X.-L. Cui, "Modified sewage sludge as temporary landfill cover material," Water Science and Engineering, vol. 8, no. 3, pp. 257-262, 2015.

[8] C. Lin, W. Zhu, and J. Han, "Permeability and leachability of solidified sewage sludge," Environmental Geotechnics, vol. 1, no. 1, pp. 33-39, 2013.

[9] J. Yang, H. Lu, X. Zhang et al., “An experimental study on solidifying municipal sewage sludge through skeleton building using cement and coal gangue," Advances in $\mathrm{Ma}$ terials Science and Engineering, vol. 2017, Article ID 5069581, 13 pages, 2017.

[10] H. Ke, J. Hu, X. B. Xu, W. F. Wang, Y. M. Chen, and L. T. Zhan, "Evolution of saturated hydraulic conductivity with compression and degradation for municipal solid waste," Waste Management, vol. 65, pp. 63-74, 2017.

[11] A. Maslahati Roudi, S. Chelliapan, W. Wan Mohtar, and H. Kamyab, "Prediction and optimization of the fenton process for the treatment of landfill leachate using an artificial neural network," Water, vol. 10, no. 5, p. 595, 2018.

[12] W.-J. Zhang, G.-G. Zhang, and Y.-M. Chen, "Analyses on a high leachate mound in a landfill of municipal solid waste in China," Environmental Earth Sciences, vol. 70, no. 4, pp. 1747-1752, 2013.

[13] G. Di Bella, D. Di Trapani, G. Mannina, and G. Viviani, "Modeling of perched leachate zone formation in municipal solid waste landfills," Waste Management, vol. 32, no. 3, pp. 456-462, 2012.

[14] H. J. He, J. W. Lan, and Y. M. Chen, "Monitoring and analysis of slope slip process ata landfillin NorthwestChina," Chinese Journal of Geotechnical Engineering, vol. 37, no. 9, pp. 17211726, 2015.

[15] EPA, Guidance Note on Daily and Intermediate Cover at Landfills, Environmental Protection Agency, Wexford, Ireland, 2014.

[16] Ministry of Housing and Urban-Rual Development of PRC (MOHURD), GB/T23485-2009, Disposal of sludge from $\mathrm{Mu}$ nicipal Wastewater Treatment Plant-Quality of Sludge for CoLandfill, Ministry of Housing and Urban-Rual Development of PRC (MOHURD), Beijing, China, 2009, in Chinese.

[17] C. F. Berg and R. Held, "Fundamental transport property relations in porous media incorporating detailed pore structure description," Transport in Porous Media, vol. 112, no. 2, pp. 467-487, 2016.

[18] J. Koestel, A. Dathe, T. H. Skaggs et al., "Estimating the permeability of naturally structured soil from percolation theory and pore space characteristics imaged by X-ray," Water Resources Research, vol. 54, no. 11, pp. 9255-9263, 2018.

[19] J. A. P. Pollacco, T. Webb, S. McNeill et al., "Saturated hydraulic conductivity model computed from bimodal water retention curves for a range of New Zealand soils," $\mathrm{Hy}$ drology and Earth System Sciences, vol. 21, no. 6, pp. 2725-2737, 2017.

[20] M. Kutílek, "Soil hydraulic properties as related to soil structure," Soil and Tillage Research, vol. 79, no. 2, pp. 175184, 2004.

[21] A. Magdziarz and S. Werle, "Analysis of the combustion and pyrolysis of dried sewage sludge by TGA and MS," Waste Management, vol. 34, no. 1, pp. 174-179, 2014.
[22] Q. Wang, W. Wei, Y. Gong et al., "Technologies for reducing sludge production in wastewater treatment plants: state of the art," Science of the Total Environment, vol. 587-588, pp. 510-521, 2017.

[23] H. H. Gerke and M. T. Van Genuchten, "A dual-porosity model for simulating the preferential movement of water and solutes in structured porous media," Water Resources Research, vol. 29, no. 2, pp. 305-319, 1993.

[24] China Planning Press, GB/T 50123-1999, Standard for Soil Test Method, China Planning Press, Beijing, China, 1999.

[25] X. H. Sun, W. Zhu, X. D. Qian, and Z. R. Xu, "Exploring cementitious additives for sewage sludge pretreatment with high early-strength from the perspective of the rapid generation of nonevaporable water," Journal of Materials in Civil Engineering, vol. 26, no. 5, 2013.

[26] ASTM, "Standard test methods for measurement of hydraulic conductivity of saturated porous materials using a flexible wall permeameter," in ASTM D5084-16a, ASTM International, West Conshohocken, PA, USA, 2016.

[27] E. T. Elliott, "Aggregate structure and carbon, nitrogen, and phosphorus in native and cultivated Soils1," Soil Science Society of America Journal, vol. 50, no. 3, pp. 627-633, 1986.

[28] F. Min, J. Du, N. Zhang et al., "Experimental study on property change of slurry and filter cake of slurry shield under seawater intrusion," Tunnelling and Underground Space Technology, vol. 88, pp. 290-299, 2019.

[29] A. Reatto, E. M. da Silva, A. Bruand, E. S. Martins, and J. E. F. W. Lima, "Validity of the centrifuge method for determining the water retention properties of tropical soils," Soil Science Society of America Journal, vol. 72, no. 6, pp. 15471553, 2008.

[30] S. Wang, W. Zhu, X. Qian, H. Xu, and X. Fan, "Study of threshold gradient for compacted clays based on effective aperture," Environmental Earth Sciences, vol. 75, no. 8, p. 693, 2016.

[31] N. Lu and W. J. Likos, Unsaturated Soil Mechanics, Wiley, Hoboken, NJ, USA, 2004.

[32] A. R. Dexter and G. Richard, "The saturated hydraulic conductivity of soils with n-modal pore size distributions," Geoderma, vol. 154, no. 1-2, pp. 76-85, 2009.

[33] C. Lin, W. Zhu, and J. Han, "Strength and leachability of solidified sewage sludge with different additives," Journal of Materials in Civil Engineering, vol. 25, no. 11, pp. 1594-1601, 2013.

[34] B. C. O'Kelly, "Geotechnical properties of municipal sewage sludge," Geotechnical \& Geological Engineering, vol. 24, no. 4, pp. 833-850, 2006.

[35] S. Y. Yuan, X. F. Liu, and O. Buzzi, "Effects of soil structure on the permeability of saturated Maryland clay," Géotechnique, vol. 69, no. 1, pp. 72-78, 2019.

[36] H. Al-Dakheeli and R. Bulut, "Interrelationship between elastic deformation and soil-water characteristic curve of expansive soils," Journal of Geotechnical and Geoenvironmental Engineering, vol. 145, no. 4, article 04019005, 2019.

[37] G. M. Laudone, G. P. Matthews, A. S. Gregory, N. R. A. Bird, and W. R. Whalley, "A dual-porous, inverse model of water retention to study biological and hydrological interactions in soil," European Journal of Soil Science, vol. 64, no. 3, pp. 345-356, 2013.

[38] S. C. Chin, D. Ing, A. Kusbiantoro, Y. K. Wong, and S. W. Ahmad, "Characterisation of sewage sludge ash (SSA) in cement mortar," ARPN Journal of Engineering and Applied Sciences, vol. 11, no. 2242, article e2247, 2016.

[39] L. Alarcon-Ruiz, G. Platret, E. Massieu, and A. Ehrlacher, "The use of thermal analysis in assessing the effect of 
temperature on a cement paste," Cement and Concrete research, vol. 35, no. 3, pp. 609-613, 2005.

[40] H. W. Olsen, "Hydraulic flow through saturated clays," Clays and Clay Minerals, vol. 9, no. 1, pp. 131-161, 1960.

[41] R. J. Luxmoore, "Micro-, meso-, and macroporosity of soil," Soil Science Society of America Journal, vol. 45, no. 3, pp. 671-672, 1981.

[42] Y. Watabe, S. Leroueil, and J.-P. Le Bihan, "Influence of compaction conditions on pore-size distribution and saturated hydraulic conductivity of a glacial till," Canadian Geotechnical Journal, vol. 37, no. 6, pp. 1184-1194, 2000.

[43] O. Cuisinier, J.-C. Auriol, T. Le Borgne, and D. Deneele, "Microstructure and hydraulic conductivity of a compacted lime-treated soil," Engineering geology, vol. 123, no. 3, pp. 187-193, 2011.

[44] Y. Deng, X. Yue, S. Liu, Y. Chen, and D. Zhang, "Hydraulic conductivity of cement-stabilized marine clay with metakaolin and its correlation with pore size distribution," Engineering Geology, vol. 193, pp. 146-152, 2015. 


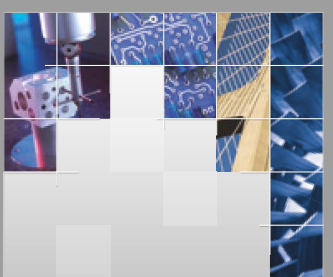

\section{Enfincering}
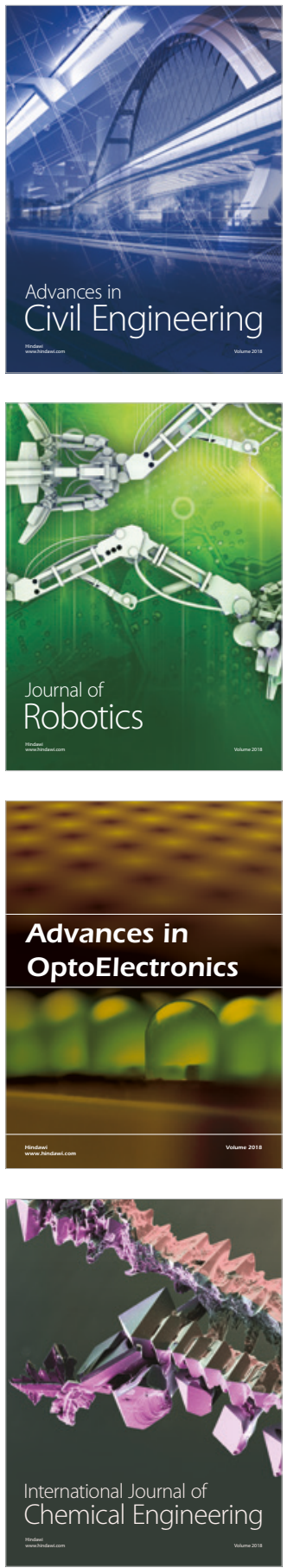

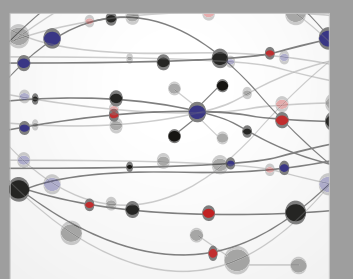

\section{Rotating \\ Machinery}

The Scientific World Journal

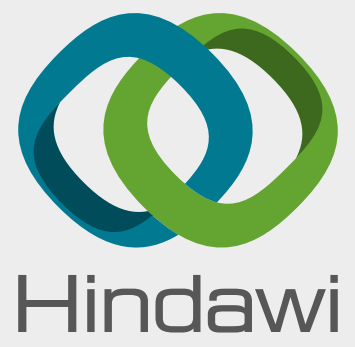

Submit your manuscripts at

www.hindawi.com
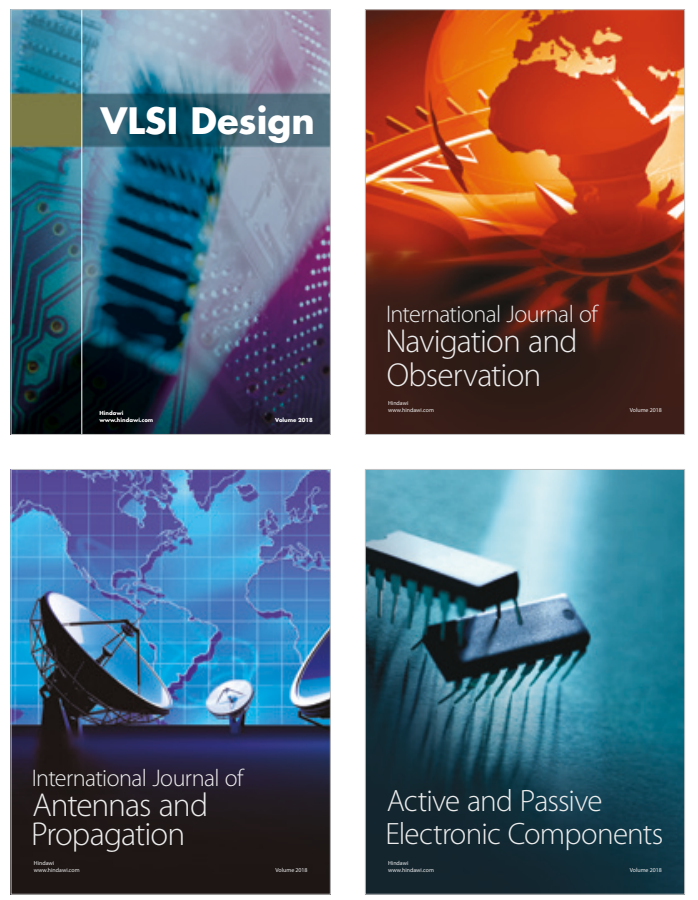
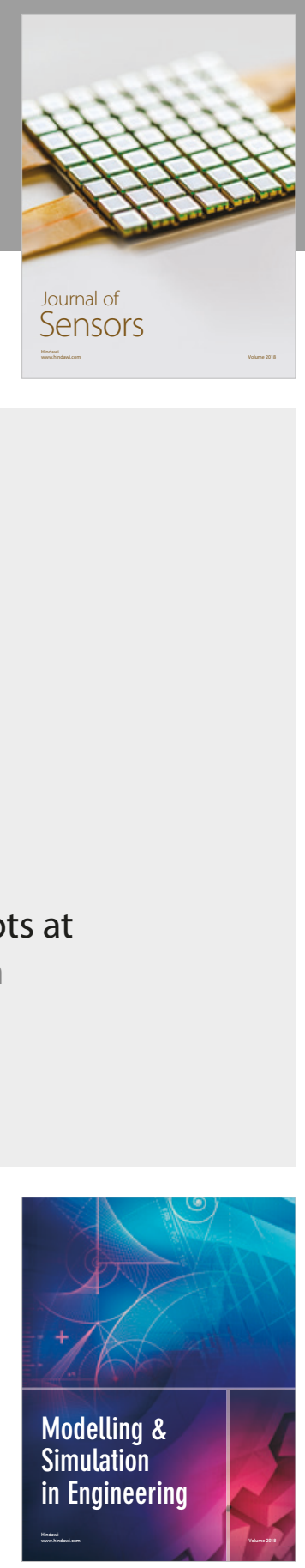

\section{Advances \\ Multimedia}
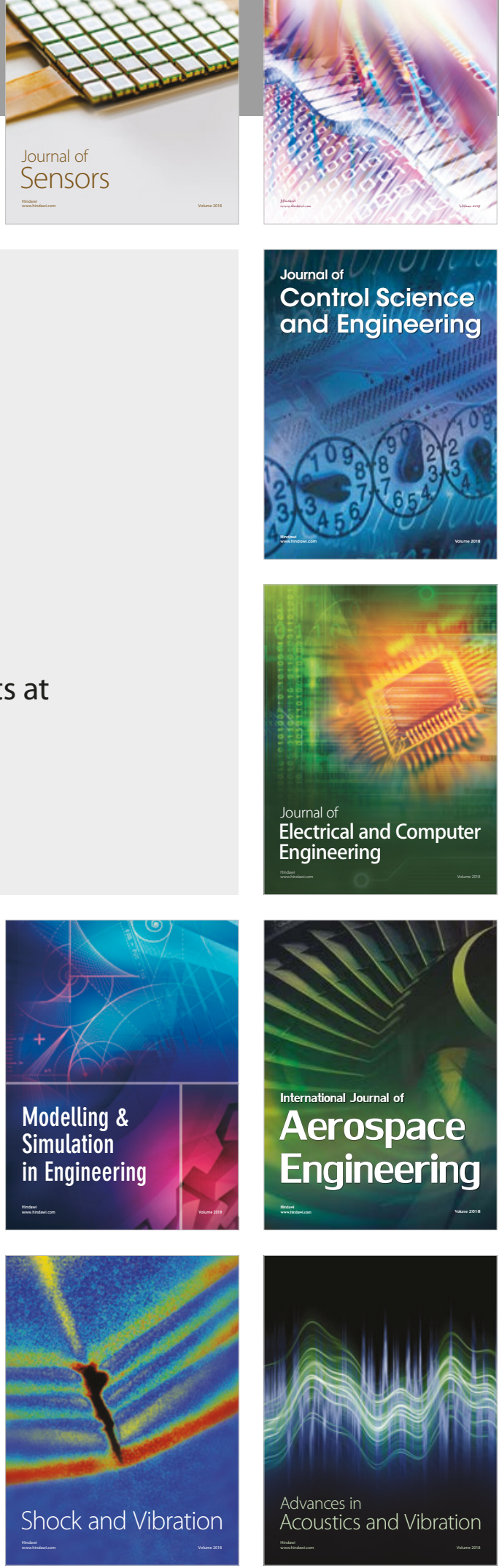